Article

\title{
Phylogeny and Mycotoxin Characterization of Alternaria Species Isolated from Wheat Grown in Tuscany, Italy
}

\author{
Francesca A. Ramires ${ }^{1,+}$, Mario Masiello ${ }^{1,+}$, Stefania Somma ${ }^{1}$, Alessandra Villani ${ }^{1}$, \\ Antonia Susca ${ }^{1}\left(\mathbb{D}\right.$, Antonio F. Logrieco ${ }^{1}$, Carlos Luz ${ }^{2}$, Giuseppe Meca ${ }^{2}$ and Antonio Moretti ${ }^{1, *}$ \\ 1 Institute of Sciences of Food Production, Research National Council (CNR-ISPA), Via Amendola 122/O, \\ 70126 Bari, Italy; francesca.ramires@ispa.cnr.it (F.A.R.); mario.masiello@ispa.cnr.it (M.M.); \\ stefania.somma@ispa.cnr.it (S.S.); alessandra.villani@ispa.cnr.it (A.V.); antonella.susca@ispa.cnr.it (A.S.); \\ antonio.logrieco@ispa.cnr.it (A.F.L.) \\ 2 Department of Preventive Medicine, Nutrition and Food Science Area, University of Valencia (Spain), \\ Avenida Vicent Andres Estelles s/n, 46100 Burjassot, Valencia, Spain; carlos.luz@uv.es (C.L.); \\ giuseppe.meca@uv.es (G.M.) \\ * Correspondence: antonio.moretti@ispa.cnr.it \\ + These authors contributed equally to this work.
}

Received: 15 October 2018; Accepted: 9 November 2018; Published: 14 November 2018

\begin{abstract}
Wheat, the main source of carbohydrates worldwide, can be attacked by a wide number of phytopathogenic fungi, included Alternaria species. Alternaria species commonly occur on wheat worldwide and produce several mycotoxins such as tenuazonic acid (TA), alternariol (AOH), alternariol-monomethyl ether (AME), and altenuene (ALT), provided of haemato-toxic, genotoxic, and mutagenic activities. The contamination by Alternaria species of wheat kernels, collected in Tuscany, Italy, from 2013 to 2016, was evaluated. Alternaria contamination was detected in 93 out of 100 field samples, with values ranging between 1 and $73 \%$ (mean of $18 \%$ ). Selected strains were genetically characterized by multi-locus gene sequencing approach through combined sequences of allergen alt1a, glyceraldeyde-3-phosphate dehydrogenase, and translation elongation factor $1 \alpha$ genes. Two well defined groups were generated; namely sections Alternaria and Infectoriae. Representative strains were analyzed for mycotoxin production. A different mycotoxin profile between the sections was shown. Of the 54 strains analyzed for mycotoxins, all strains included in Section Alternaria produced $\mathrm{AOH}$ and AME, 40 strains $(99 \%)$ produced TA, and 26 strains $(63 \%)$ produced ALT. On the other hand, only a very low capability to produce both AOH and AME was recorded among the Section Infectoriae strains. These data show that a potential mycotoxin risk related to the consumption of Alternaria contaminated wheat is high.
\end{abstract}

Keywords: tenuazonic acid; alternariol; alternariol-monomethyl ether; altenuene; Section Alternaria; Section Infectoriae; allergen alt1a; glyceraldeyde-3-phosphate dehydrogenase; translation elongation factor $1 \alpha$

Key Contribution: The paper underlines the high risk of Alternaria mycotoxin contamination of wheat kernels in field. Also, the paper shows that there is a need for correct identification at species level, because of the peculiarity of mycotoxin profile of each species.

\section{Introduction}

Since ancient times, wheat has been one of the most cultivated cereals worldwide, representing an important source of carbohydrates in human and livestock diet. Italy is one of the most important 
producers at worldwide level with production of around 3 million of tons of soft wheat and 4.5 million of tons of durum wheat in 2018 [1].

Under specific pedo-climatic conditions, wheat plants can be colonized by several fungal species since the early growth stages, although the flowering stage is the most susceptible period for fungal colonization. As a consequence, kernels can be colonized by several toxigenic fungal species, mainly belonging to Fusarium and Alternaria genera. These fungal genera negatively influence quantitative and qualitative wheat production and they represent a serious toxicological risk as they produce a broad spectrum of mycotoxins and secondary metabolites, which can cause problems in humans and animals [2] (pp. 51-57).

Several Alternaria species colonize wheat plants, causing symptoms on both leaf and kernels. In particular, some Alternaria species, such as A. triticina, colonize wheat leaf causing leaf spot disease [3-5]. On the other hand, A. alternata, A. arborescens, A. infectoria, A. tenuissima, and A. triticina are common colonizers of wheat kernels, being associated with black point disease at worldwide level [6-8].

Wheat kernels infected by Alternaria species are characterized by black pigmentation in the underlying embryo region, which causes a reduction in flour quality for the release of black points in the flour and in the resulting bread baked, and the loss of nutritional value with a decrease of starch and soluble carbohydrates, and increase of phenolics, prolamin, and gluten content [9]. In addition, the food consumption of Alternaria contaminated wheat may be a major risk to human health, as many Alternaria species produce several metabolites, which are toxic for humans and animals $[6,10,11]$.

The most important Alternaria mycotoxins are the dibenzopyrone derivatives alternariol $(\mathrm{AOH})$, alternariolmonomethyl ether (AME), and altenuene (ALT); the tetramic acid derivatives tenuazoic acid (TA); the cyclic tetrapeptidetentoxin (TEN); the perylene derivatives alterotoxins (ATX-I, ATX-II, ATX-III); and the sphinganine-analog Alternaria alternata f. sp. lycopersici toxin (AAL toxin) [6,12-14].

Several studies demonstrate the toxicological risk linked to these metabolites. The mycotoxins $\mathrm{AOH}$ and AME show genotoxic activity on human cell lines of colon cancer [11]. The consumption of wheat highly contaminated by $\mathrm{AOH}$ and $\mathrm{AME}$ was significantly related to elevated levels of human esophageal cancer in China [15]. Tenuazoic acid has been associated with human hematologic disorder called "onalay", in central and southern Africa [16]. Moreover, in another study, this myicotoxin was observed to induce precancerous changes in the esophageal mucosa of mice [17]. Altertoxin I showed high acute toxicity in mice and mutagenicity of mammalian cells lines [18]; moreover, ATX I and ATX-III were shown to be potent mutagens and tumor promoters [11]. Finally, the sphinganine-analog AAL-toxin is harmful to humans, causing apoptosis of mammalian cells interfering with ceramide biosynthesis [10]. Altogether, Alternaria mycotoxins have been associated with colon-rectal cancer, occurring significantly in food consummated by humans affected by this pathology [19]. For this reason, in recent decades, food and feed contamination by mycotoxins produced by Alternaria species is a main issue, as the European Food Safety Authority (EFSA) has highlighted [2]. Deeper studies about toxic effects of these metabolites and monitoring activities to detect the presence of Alternaria toxins in food and feed are encouraged in order to define and evaluate risk exposure in European Union countries.

Among Alternaria species occurring on wheat kernels, a species-specific mycotoxin profile has not been identified. However, the species A. alternata, A. tenuissima, and A. arborescens have been reported able to produce AOH, AME, ATX-I, II, III, TA, and TEN [6,12-14]. On the other hand, A. infectoria species seem unable to produce mycotoxins [6]. Therefore, a correct identification of Alternaria strains occurring on wheat kernels is needed in order to better define the potential risk of their accumulation in the final products. However, such identification at species level is very difficult in this genus because of their highly controversial taxonomic "status" [8]. The first approach widely used in Alternaria species identification has been for several years based on the observation of phenotypical characters as sporulation pattern, total length of the primary conidiophores, type and origin of branching, conidial shape, and orientation [20]. Subsequently, the DNA-based species identification is becoming prevalent, by analyzing DNA fingerprinting (RAPD, PCR-RFLP, AFLP, and ISSR) or DNA and protein-coding 
gene sequences, such as glyceraldehyde 3-phosphate dehydrogenase, endopolygalacturonase, and $\beta$-tubulin, allergen Alt 1a [21-24]. The molecular approach based on gene sequencing allowed the promotion of important taxonomic revisions of Alternaria genus grouping species in sections [25,26]. Alternaria species are characterized by a great morphological, molecular, and mycotoxin variability. Therefore, a polyphasic approach based on morphological, mycotoxin profile, and molecular characterization has been suggested for a correct identification [27].

In this paper, we investigated and characterized an Alternaria set of strains from wheat in Tuscany, to monitor it in the same geographical area along four consecutive crop seasons, from 2013 to 2016. The aims were as follows: (a) to evaluate the occurrence and the dynamics of Alternaria contamination on wheat in Tuscany; (b) to morphologically and molecularly identify species within the isolated Alternaria population; and (c) to analyze the mycotoxin profile of representative strains to assess the correct Alternaria mycotoxin risk due to consumption of wheat grown in Tuscany.

\section{Results}

\subsection{Detection of Fungal Contamination}

For each sample, after five days of incubation, fungal colonies originating from infected kernels were counted and percentages of total fungal contamination and Alternaria contamination were calculated. Mean values of contamination, obtained considering host and crop seasons, are reported in Table 1. With the exception of two samples of durum wheat and one sample of soft wheat, all samples were highly contaminated by fungal species with values of fungal contamination ranging between 47 and $100 \%$. Besides Alternaria, the main occurring fungal genera were Fusarium and, to a lesser extent, Cladosporium, Epicoccum, and Stemphylium (Table S1).

Table 1. Mean value and range of Alternaria and other fungal contamination detected in the 100 wheat samples collected throughout the Tuscany region, over four consecutive crop seasons (2013-2016).

\begin{tabular}{ccccccc}
\hline \multirow{2}{*}{ Host } & \multirow{2}{*}{ Year of Sampling } & \multirow{2}{*}{ Number of Fields } & \multicolumn{3}{c}{ Fungal Contamination (\%) } \\
\cline { 4 - 7 } & & & Alternaria spp. & \multicolumn{2}{c}{ Other Fungi } \\
\cline { 4 - 7 } & 2013 & 10 & $0-31$ & 17 & $36-82$ & 68 \\
\multirow{3}{*}{ Soft wheat } & 2014 & 16 & $0-17$ & 4 & $19-95$ & 73 \\
& 2015 & 11 & $4-73$ & 26 & $15-81$ & 54 \\
& 2016 & 11 & $11-50$ & 33 & $36-83$ & 57 \\
\hline \multirow{3}{*}{ Durum } & 2013 & 31 & $0-48$ & 17 & $1-88$ & 55 \\
wheat & 2014 & 15 & $0-11$ & 7 & $57-93$ & 76 \\
& 2015 & 4 & $8-43$ & 26 & $36-84$ & 64 \\
& 2016 & 2 & $22-35$ & 29 & $60-77$ & 68 \\
\hline
\end{tabular}

Alternaria contamination was detected in 93 out of 100 samples. In 13 samples, Alternaria contamination values were below $10 \%$, and in the remaining 80 samples, the Alternaria occurrence ranged from $11 \%$ to $73 \%$ of contaminated kernels. The highest Alternaria contamination was detected in two fields located in Firenze province, during 2015, with values of 54 and 73\%, respectively. Overall, in soft wheat, the highest Alternaria contamination was detected in samples collected in Firenze (35\%) and Siena (36\%) provinces during 2016 crop season, while in durum wheat, the highest was detected in samples collected in Siena province during 2015 (43\%). The lowest Alternaria contamination was detected during the 2014 crop season, in all areas sampled, both in soft and durum wheat, with values ranging between 0 and 17\% (mean values of 3.6) and between 0 and 11\% (mean values of $6.3 \%$ ), respectively (Table 1 ).

Mean values of temperatures and rainfall, calculated for each crop season (2013-2016) and from heading to harvest of each crop season, are reported in Table 2. The highest rainfall was recovered in 2013, with $820 \mathrm{~mm}$ over the crop season. Moreover, the highest rainfall was associated with a 
lower mean temperature $\left(9.1^{\circ} \mathrm{C}\right.$ during the whole crop season and $14.8^{\circ} \mathrm{C}$ from heading to harvest). The highest temperature was registered during the 2016 crop season $\left(12.7^{\circ} \mathrm{C}\right)$. Considering the period from heading to harvest, in which wheat plants are most susceptible to fungal infections, the highest rainfall $(256 \mathrm{~mm})$ and temperature $\left(17.6^{\circ} \mathrm{C}\right)$ values were observed in 2016 . In the same years, the highest contamination by Alternaria species was also observed (mean value of $32.8 \%$ ). On the contrary, in the same period, from heading to harvest, the lowest levels of rain and temperature were detected in 2014 (95 mm of rain and $15^{\circ} \mathrm{C}$, respectively), associated with the lowest Alternaria contamination (mean value of $5.5 \%$ ).

Table 2. Origin, fungal contamination of wheat samples analyzed, and meteorological data collected in Tuscany.

\begin{tabular}{|c|c|c|c|c|c|c|c|}
\hline \multirow[t]{2}{*}{$\begin{array}{l}\text { Year of } \\
\text { Sampling }\end{array}$} & \multirow{2}{*}{$\begin{array}{l}\text { Durum } \\
\text { Wheat }^{\text {a }}\end{array}$} & \multirow{2}{*}{$\begin{array}{c}\text { Soft } \\
\text { Wheat }\end{array}$} & \multirow{2}{*}{$\begin{array}{c}\text { Alternaria } \\
\text { Contamination }(\%)\end{array}$} & \multicolumn{2}{|c|}{$\begin{array}{c}\text { Meteorological Data } \\
\text { (from Seedling to Harvest) }\end{array}$} & \multicolumn{2}{|c|}{$\begin{array}{c}\text { Meteorological Data } \\
\text { (from Heading to Harvest) }\end{array}$} \\
\hline & & & & Rainfall (mm) & Mean T & Rainfall (mm) & Mean T \\
\hline 2014 & 15 & 16 & 5.5 & 580 & 10.9 & 95 & 15 \\
\hline 2015 & 4 & 11 & 26.2 & 525 & 11.1 & 115 & 16.6 \\
\hline 2016 & 2 & 11 & 32.8 & 691 & 12.7 & 256 & 17.6 \\
\hline
\end{tabular}

From each sample, Alternaria strains were morphologically characterized. A great variability was observed based on the shape of conidia, and conidiophore branches' morphology. All strains were related to four morphospecies: A. alternata, A. tenuissima, A. arborescens, and A. infectoria [20]. Representative strains were thus subjected to gene sequencing for confirming species identification and establishing phylogenetic relationships within the investigated population.

\subsection{DNA-Based Identification}

The evolutionary history of 134 Alternaria strains was studied at the genetic level by amplifying three different fragments of gpd-, alt-, and tef1-agenes. The amplifications generated fragments of about 600, 400, and 590 nucleotides, respectively. All three gene fragments showed length polymorphisms due to intraspecific variation. To further solve the identity of the strains, the phylogenetic analysis of the concatenated sequences of the three fragments was carried out. The phylogenetic tree, obtained with Mega7 software using the maximum parsimony method, allowed us to define five well-separated clades, corresponding to Section Alternaria (A), Section Brassicicola (B), Section Porri (C), Section Infectoriae (D), and Section Pseudoalternaria (E), as determined using reference strains (Figure 1). The resolution of all the clades was supported by high bootstrap values. In Sections Brassicicola and Porri, only reference strains included in the analysis were clustered (Figure 1). In clade A (Section Alternaria), six well-defined sub-clades were obtained. Sub-clade A1 grouped 70 field strains with the reference strains A. alternata ATCC66891, A. alternata ATCC 11680, A. alternata BMP 0270, A. citrimacularis BC2-RLR-17s, A. angustiovoidea EGS 36-172, A. tenuissima BMP 0304, A. limoniasperae BMP 2335, A. perangusta BMP 2336, and A. turkisafria BMP 3436. In this sub-clade, an elevated level of homology was observed. Sub-clade A2 grouped 11 field strains with A. arborescens BMP 0308 and A. cerealis EGS 43-072 reference strains. In sub-clade A3 and sub-clade A4, only reference strains were grouped: A. fragariae BMP 3062, A. gaisen BMP 0243, and A. gaisen BMP 2338 in sub-clade A3; A. longipes BMP 0313, A. grisea CBS 107.36, A. tangelonis BMP 2327, and A. burnsii CBS 107.38 in sub-clade A4 (Figure 1). Sub-clade A5 grouped 24 field strains and the reference strains A. citriarbusti BMP 2343, A. mali BMP 3064, and A. rhadina CBS 595.93. Sub-clade A6 included only A. betae-kenyensis CBS 118810 reference strains. Clade D grouped 17 field strains and all reference strains of Alternaria species belonging to "Section Infectoriae": A. alternarina CBS 119396, A. intercepta EGS 49-137, A. incomplexa EGS 17-103, A. oregonensis EGS 29-194, A. metachromatica EGS 38-132, A. californica EGS 52-082, A. hordeicola EGS 50-184, A. conjuncta EGS 37-139, A. ethzedia EGS 37-143, A. infectoria EGS 27.193, A. photistica EGS 
35-172, A. viburni EGS 49-147, A. novae-zelandiae EGS 48-092, A. ventricosa EGS 52-075, and A. triticina EGS 17-061, in addition to 17 field strains. In particular, ITEM 17966 showed high homology with A. ethzedia EGS 37-143; ITEM 17974 showed high homology with A. metachromatica EGS 38-132; six field strains were highly similar to A. ventricosa EGS 52-075; and nine field strains were highly similar to A. triticina EGS 17-061. Clade E "Section Pseudoalternaria" grouped four field strains and A. rosae EGS 41-130 reference strains (Figure 1). More detailed information is reported in Table S2 of Supplementary Material.

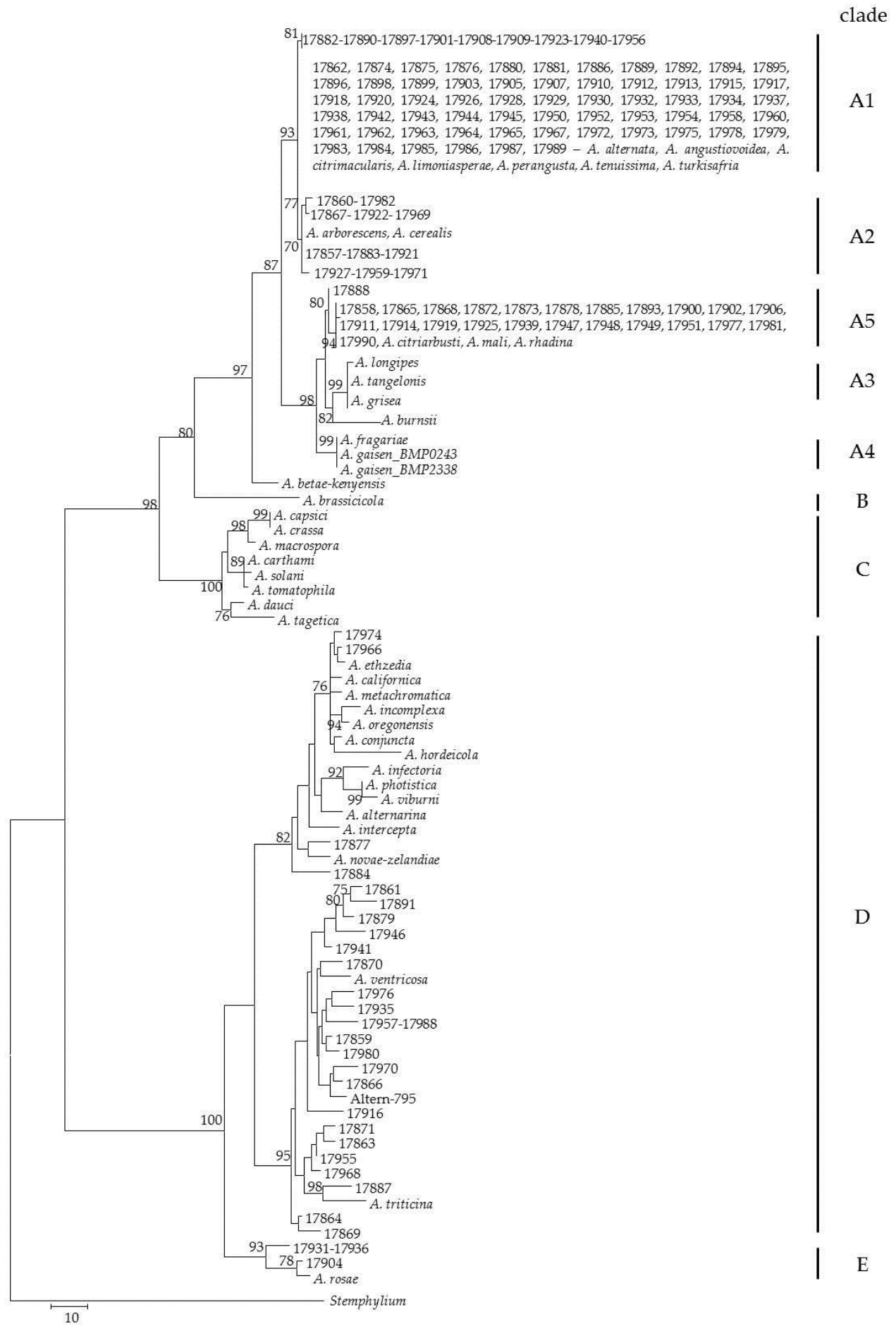

Figure 1. Phylogenetic tree generated by maximum parsimony method (bootstrap 1000 replicates) of combined alt-, gpd-, and tef-gene sequences of 134 Alternaria strains. 


\subsection{Mycotoxin Production Profile}

Fifty-four Alternaria strains were analyzed for mycotoxin profile. For each strain, AOH, AME, ALT, and TA productions were evaluated (Table 3). Chemical analyses were carried out on 41 strains included in Section Alternaria (Clade A: 28, 3, and 10 strains grouped in sub-clade A1, A2, and A5, respectively); 12 strains included in Section Infectoriae (Clade D); and 1 strain included in Section Pseudoalternaria (Clade E). With regard to AOH production, all Alternaria strains grouped in Section Alternaria (Clade A) produced this mycotoxin, in a range from 0.5 to $5620 \mathrm{mg} \cdot \mathrm{kg}^{-1}$. In Table 3 , the values for each strain analyzed are reported. In particular, $\mathrm{AOH}$ was produced at maximum values of 5620,3180 , and $3650, \mathrm{mg} \cdot \mathrm{kg}^{-1}$ for sub-clade A1, A2, and A5, respectively. Overall, $\mathrm{AOH}$ amount ranged in an interquartile between 57.1 and $1083.0 \mathrm{mg} \cdot \mathrm{kg}^{-1}$, with a median value of 342.3 $\mathrm{mg} \cdot \mathrm{kg}^{-1}$ (Figure 2). On the other hand, all strains grouped in Section Infectoriae produced $\mathrm{AOH}$ at a very low level (mean value $4 \mathrm{mg} \cdot \mathrm{kg}^{-1}$; range $0.3-20 \mathrm{mg} \cdot \mathrm{kg}^{-1}$ ). In particular, $\mathrm{AOH}$ amount ranged in an interquartile between 0.7 and $9.1 \mathrm{mg} \cdot \mathrm{kg}^{-1}$, with a median value of $2.6 \mathrm{mg} \cdot \mathrm{kg}^{-1}$ (Figure 2). Also, the only Section Pseudoalternaria strain analyzed, ITEM 17904 (Figure 1), produced a low amount of $\mathrm{AOH}\left(1.5 \mathrm{mg} \cdot \mathrm{kg}^{-1}\right)$.

Table 3. Mycotoxin production by Alternaria strains isolated from wheat in Tuscany.

\begin{tabular}{|c|c|c|c|c|c|c|c|c|c|}
\hline \multirow{2}{*}{ Strain ${ }^{a}$} & \multicolumn{4}{|c|}{ Mycotoxin $\left(\mathrm{mg} \cdot \mathrm{kg}^{-1}\right) \mathrm{b}$} & \multirow{2}{*}{ Strain ${ }^{a}$} & \multicolumn{4}{|c|}{ Mycotoxin $\left(\mathrm{mg} \cdot \mathrm{kg}^{-1}\right)^{b}$} \\
\hline & AOH & AME & ALT & TA & & AOH & AME & ALT & TA \\
\hline \multicolumn{5}{|c|}{ Alternaria Section Sub-Clade A1 } & \multicolumn{5}{|c|}{ Alternaria Section Sub-Clade A5 } \\
\hline 17,862 & 60 & 710 & n.d. & 150 & 17,888 & 95 & 1450 & n.d. & 165 \\
\hline 17,874 & 350 & 1440 & 140 & 305 & 17,893 & 335 & 3 & 10 & 17 \\
\hline 17,875 & 475 & 2400 & 175 & 345 & 17,900 & 1225 & 2700 & 1 & 255 \\
\hline 17,876 & 960 & 1700 & 120 & 350 & 17,902 & 835 & 15 & n.d. & 130 \\
\hline 17,880 & 970 & 15,150 & n.d. & n.d. & 17,906 & 0.5 & 2 & 3 & 5.5 \\
\hline 17,881 & 505 & 2385 & 15 & 60 & 17,865 & 385 & 1125 & 0.5 & 40 \\
\hline 17,882 & 480 & 1420 & n.d. & 235 & 17,868 & 1290 & 3315 & n.d & 155 \\
\hline 17,886 & 65 & 480 & 5 & 30 & 17,873 & 100 & 724 & 130 & 60 \\
\hline 17,887 & 4.5 & 15 & 15 & 20 & 17,878 & 20 & 12.5 & 3 & 12.5 \\
\hline 17,889 & 2780 & 13,230 & 180 & 230 & 17,885 & 3650 & 17,415 & 4 & 170 \\
\hline 17,890 & 58 & 475 & 30 & 80 & Average & 794 & 2676 & 15 & 101 \\
\hline 17,892 & 96 & 20 & 16 & 75 & Min Value & 1 & 2 & 0 & 6 \\
\hline 17,894 & 375 & 1260 & 22 & 42 & Max value & 3650 & 17415 & 130 & 255 \\
\hline 17,895 & 95 & 220 & n.d. & 272 & \multicolumn{5}{|c|}{ Infectoriae Section Clade D } \\
\hline 17,896 & 1465 & 11,710 & 3.5 & 848 & 17,859 & 1.5 & 4 & n.d. & 105 \\
\hline 17,897 & 3090 & 11,950 & 9 & 10 & 17,861 & 2.5 & 23 & 1.5 & 4 \\
\hline 17,898 & 110 & 230 & 1.0 & 170 & 17,863 & 2.5 & 1 & 8.5 & n.d. \\
\hline 17,899 & 1120 & 2050 & 2.5 & 660 & 17,864 & 3 & 3 & n.d. & 10 \\
\hline 17,901 & 60 & 75 & n.d. & 145 & 17,866 & 3.5 & 10 & n.d. & n.d. \\
\hline 17,903 & 730 & 3910 & n.d. & 430 & 17,869 & 0.5 & 6 & n.d. & n.d. \\
\hline 17,905 & 70 & 80 & n.d. & 23 & 17,870 & 0.5 & 2 & n.d. & n.d. \\
\hline 17,907 & 485 & 2335 & n.d. & 175 & 17,871 & 10 & 6 & n.d. & n.d. \\
\hline 17,908 & 75 & 215 & n.d. & 20 & 17,877 & 2.5 & 2.5 & n.d. & n.d. \\
\hline 17,909 & 14 & 7 & 7.5 & 25 & 17,879 & 0.5 & 0.5 & n.d. & 415 \\
\hline 17,910 & 2670 & 5096 & n.d. & 185 & 17,884 & 20 & 15 & 10 & 40 \\
\hline 17,912 & 25 & 15 & 7 & 50 & 17,891 & 2 & 1 & 0.2 & 90 \\
\hline 17,858 & 5620 & 5290 & 1.5 & 65 & Average & 4 & 6 & 2 & 55 \\
\hline 17,911 & 770 & 1970 & 0.5 & 30 & Min Value & 0.3 & 0.5 & 0 & 0 \\
\hline Average & 842 & 3066 & 27 & 180 & Max value & 20 & 23 & 10 & 415 \\
\hline Min Value & 5 & 7 & 0 & 0 & - & \multicolumn{4}{|c|}{ Pseudoalternaria Section Clade E } \\
\hline Max value & 5620 & 15150 & 180 & 848 & 17,904 & 1.5 & 5.5 & 10 & n.d. \\
\hline \multicolumn{5}{|c|}{ Alternaria Section Sub-Clade A2 } & & & & & \\
\hline 17,857 & 3180 & 1215 & 0.5 & 7 & & & & & \\
\hline 17,867 & 1835 & 810 & n.d. & 7.5 & & & & & \\
\hline 17,883 & 2.5 & 10 & n.d. & 100 & & & & & \\
\hline Average & 1673 & 678 & 0.2 & 38 & & & & & \\
\hline Min Value & 2.5 & 10 & 0.0 & 7 & & & & & \\
\hline Max value & 3180 & 1215 & 0.5 & 100 & & & & & \\
\hline
\end{tabular}


$\mathrm{AOH}$

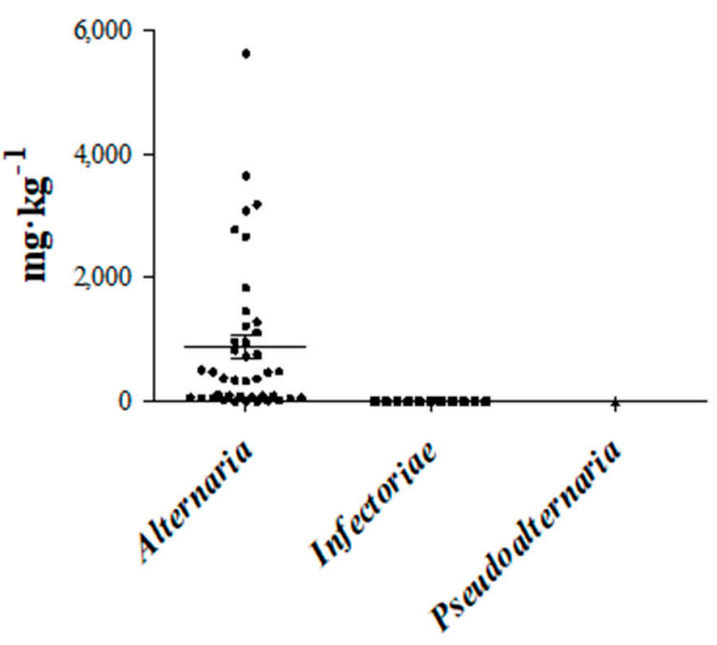

ALT

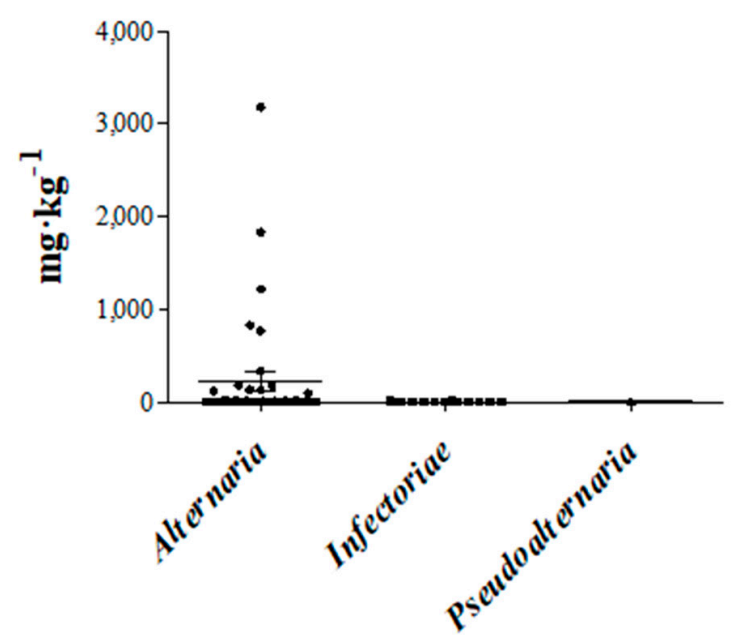

AME

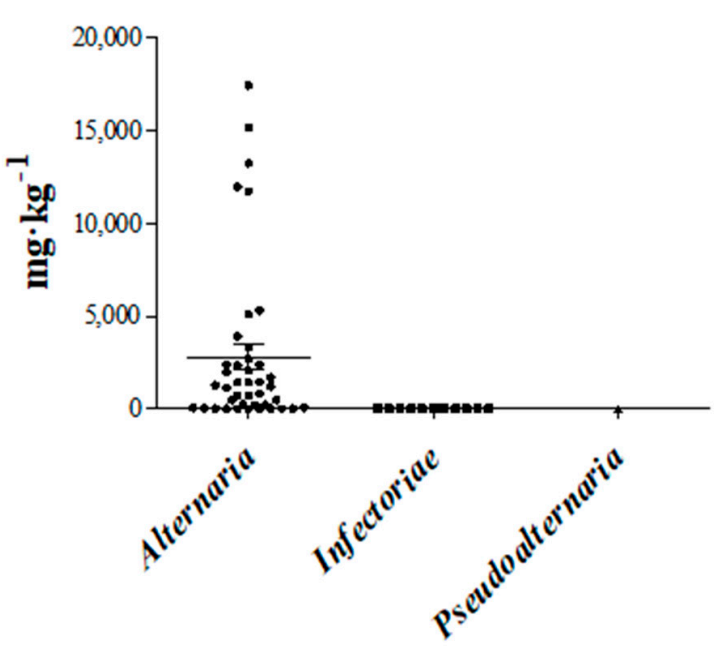

TA

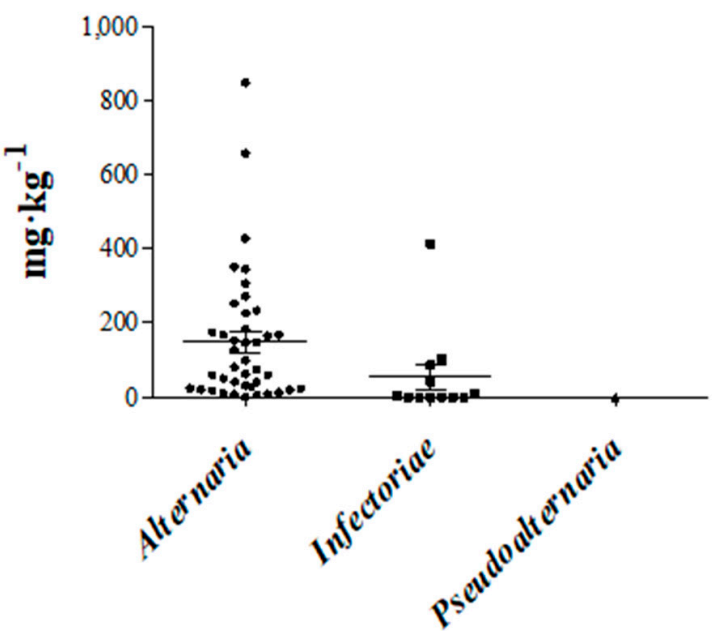

Figure 2. Scatter plot for four examined Alternaria mycotoxins: alternariol (AOH), alternariol mono methyl ether (AME), altenuene (ALT), and tenuazonic acid (TA). Production values represent Alternaria strains belonging to Section Alternaria, Infectoriae, and Pseudoalternaria. Interquartile and median values are reported in the graphs.

The production of AME has a similar trend to that of $\mathrm{AOH}$. All strains grouped in Section Alternaria produced AME with mean values of 3066, 678, and $2676 \mathrm{mg} \cdot \mathrm{kg}^{-1}$ for A1, A2, and A5 sub-clades, respectively (Table 3). In Section Alternaria, AME amount ranged in an interquartile between 24.9 and $2392.0 \mathrm{mg} \cdot \mathrm{kg}^{-1}$ (median value of $776.4 \mathrm{mg} \cdot \mathrm{kg}^{-1}$; Figure 2). All strains of the Section Infectoriae produced a very low amount of this mycotoxin (interquartile ranging between 1.4 and $18.0 \mathrm{mg} \cdot \mathrm{kg}^{-1}$ with a median value of $\left.6 \mathrm{mg} \cdot \mathrm{kg}^{-1}\right)$. The strain analyzed belonging to Section Pseudoalternaria produced also a very low amount of AME: $5.5 \mathrm{mg} \cdot \mathrm{kg}^{-1}$ (Table 3).

The production of ALT was low for both Sections Alternaria and Infectoriae. In Section Alternaria, 10 out of 28 strains grouped in sub-clade A1, 2 out of 3 strains grouped in sub-clade A2, and 3 out of 10 strains grouped in sub-clade A5 did not produce ALT. Moreover, the ALT amount did not exceed values of $180,0.5$, and $130 \mathrm{mg} \cdot \mathrm{kg}^{-1}$ for A1, A2, and A5, respectively (Table 3). In Section Alternaria, ALT amount ranged in an interquartile between 0 and $12.6 \mathrm{mg} \cdot \mathrm{kg}^{-1}$, with a median value of $1.2 \mathrm{mg} \cdot \mathrm{kg}^{-1}$ (Figure 2). In Section Infectoriae (interquartile ranging between 0.0 and $6.8 \mathrm{mg} \cdot \mathrm{kg}^{-1}$ with a median value of $0.1 \mathrm{mg} \cdot \mathrm{kg}^{-1}$, Figure 2), only four strains out of twelve produced ALT with 
a range of $0.2-9.6 \mathrm{mg} \cdot \mathrm{kg}^{-1}$ and a mean of value of $1.7 \mathrm{mg} \cdot \mathrm{kg}^{-1}$. Finally, the Section Pseudoalternaria strain produced $10 \mathrm{mg} \cdot \mathrm{kg}^{-1}$ of ALT (Table 3).

With regard to TA production, all strains included in Section Alternaria, with the exception of ITEM 17880 (sub-clade A2), were able to produce the mycotoxin in an interquartile range between 17.9 and $180.8 \mathrm{mg} \cdot \mathrm{kg}^{-1}$, with a median value of $68.6 \mathrm{mg} \cdot \mathrm{kg}^{-1}$ (Figure 2). On the other hand, in Section Infectoriae (interquartile ranging between 0.0 and $75.4 \mathrm{mg} \cdot \mathrm{kg}^{-1}$; median value of $11.4 \mathrm{mg} \cdot \mathrm{kg}^{-1}$, Figure 2), a great variability in TA production was observed. Six out of twelve strains did not produce TA, while the six producer stains ranged from 4 to $415 \mathrm{mg} \cdot \mathrm{kg}^{-1}$ (Table 3). The strain of Section Pseudoalternaria analyzed did not produce TA.

\section{Discussion}

This paper focused on the characterization of an Alternaria population isolated from wheat, exploiting, in four consecutive crop seasons (2013-2016), an extensive monitoring activity of both durum and soft wheat samples collected in Tuscany, central Italy, a particularly suitable region for wheat production. Italy is among the most important producers of wheat and wheat-derived food worldwide, and much attention is addressed to quality agricultural productions being characterized as the "Made in Italy" foodstuffs. Since decades ago, several studies have been carried out to monitor mycotoxigenic fungal species and mycotoxin contamination on wheat and other cereals in Italy [28,29]. However, almost all studies were focused on Fusarium and related mycotoxins, while Alternaria occurrence has been poorly investigated. Black point disease has been considered for a long time as a qualitative and commercial problem, linked to both release of black points in flour and baked bread, as well as loss of nutritional value [9]. Several studies have demonstrated the toxicological risks of Alternaria mycotoxins on both human and animals [11,30,31]. Furthermore, EFSA (European Food Safety Agency) triggered the need for deeper studies on Alternaria species and related mycotoxin occurrence risk on foodstuffs [2], while specific regulation for Alternaria mycotoxins is under evaluation at European Union level. The samples analyzed in this study were highly contaminated by fungal species belonging mainly to Alternaria, Cladosporium, Epicoccum, Fusarium, and Stemphylum genera (97 samples out of 100). Alternaria occurrence was very high in terms of incidence and frequency. Indeed, 80 out of the 100 samples analyzed were contaminated by Alternaria at a value higher than $10 \%$ of kernels. This high level of contamination highlights the wide risk of Alternaria mycotoxin occurrence, as many of the species identified are able to produce mycotoxins. However, the taxonomy of the Alternaria genus is a very controversial issue. Indeed, many studies have been devoted to Alternaria and related genera, often confirming a confused taxonomic background, which has caused a continuous process of taxonomic revision. In our work, the strains were phylogenetically identified as belonging mostly to Section Alternaria and, to a lesser extent, to Section Infectoriae, while the occurrence of Section Pseudoalternaria strains was rare. Therefore, because of the presence of several toxigenic species among those belonging to Section Alternaria, a correct identification of most occurring species on wheat is not only useful to define their identity, but is also of key importance to assess the toxicological risk caused by the Alternaria species associated to wheat.

The Alternaria strains collected were morphologically identified according to Simmons [20] as A. alternata, A. tenuissima, A. arborescens, and A. infectoria. Several studies reported A. alternata, A. tenuissima, and $A$. infectoria as the most frequent Alternaria species isolated from wheat-infected kernels [12,32,33]. Alternaria arborescens has been also identified in wheat, as reported in recent studies in Argentina [12,34], Tunisia [35], Germany, and Russia [33]. However, an identification based only on morphological characters can bring misidentification. Thus, for a more reliable identification at species level, we applied a polyphasic approach to our set of Alternaria strains, based not only on morphology, but also on genetic and mycotoxin characterization $[8,23,25,36]$. The three genes used for a multi-locus sequence approach ( $g p d$, tef, alt-1a) were selected because, from previous studies, they proved to be highly informative in Alternaria [8,26,36,37]. All strains were grouped into three sections: Alternaria, Infectoriae, and Pseudoalternaria, according to Woudemberg et al. [26,36] and Lawrence et al. [38]. 
In Section Alternaria, 105 strains were included, with the A. alternata and A. tenuissima morphospecies being the most widespread species. On the other hand, the phylogenetic tree based on the three genes used in the present work (Figure 1) confirmed that the species A. alternata, A. tenuissima, A. citrimacularis, A. angustiovoidea, A. limoniasperae, $A$. perangusta, and $A$. turkisafria are genetically indistinguishable, as reported in Woudenberg et al. [26,36] and in Somma et al. [8]. Thus, we support the suggestion of the above-mentioned authors to synonymize these species in the single species A. alternata.

Twenty-seven Alternaria strains were grouped in Section Infectoriae, sharing a high level of similarity. In particular, almost all the strains (24 strains) clustered with the reference strains $A$. triticina EGS17-061 and A. ventricosa EGS52-075. Alternaria triticina is the main Alternaria species associated with leaf spot disease of wheat plants, rarely reported as species capable to cause infection of wheat kernels [7]. Moreover, the strain ITEM 17974 clustered with A. metachromatica and A. californica reference strains; the strain ITEM 17966 was identified as A. ethzedia; the strain ITEM 17877 showed a very high level of similarity to $A$. novae-zelandiae. While $A$. metachromatica and $A$. californica were already reported on wheat $[20,39]$ (p. 602), this is the first study reporting the occurrence on wheat of A. ethzedia and A. novae-zelandiae, which are common pathogens of Brassica plants and carrot, respectively $[40,41]$.

Only three strains (ITEM 17904, ITEM 17931, and ITEM 17936) were identified as belonging to Section Pseudoalternaria, the species of which have been reported, by Poursafar et al. [42], as occurring on black point affected cereals only in Iran. This section has been only recently described by Lawrence et al. [25,37], on the behalf of its taxonomic revision of Alternaria genus. However, our phylogenetic tree clearly describes this section as being merged in the wider Section Infectoriae, thus questioning its separated identity as a section. Indeed, the three above-mentioned strains showed higher genetic similarity with reference strains of $A$. triticina and $A$. ventricosa, than with the reference strains of other Section Infectoriae species, such as A. infectoria. This is clear evidence that the separation of Section Pseudoalternaria within Alternaria genus needs more robust genetic support to be accepted.

We investigated whether Alternaria population structure was related to crop season and host species, but no differences have been observed. Also, the species identified were all able to colonize both durum and soft wheat, at the same frequency. Only strains genetically identified as $A$. mali showed a significant prevalence on a given host, because they were isolated with an evidently higher frequency from durum wheat than soft wheat (20 strains out of the total 24 strains isolated).

Finally, the representative strains of the different clades, generated from the phylogenetic analysis, were chemically characterized through the determination of their in vitro mycotoxin production by verifying the toxicological risk associated with the occurrence of Alternaria strains isolated in kernel samples. The Section Infectoriae strains produced low amounts of AOH, AME, ALT, and TA, however, several of the Section Alternaria strains produced all tested mycotoxins at very high levels, indicating that a potential risk for a significant contamination of AOH, AME, ALT, and TA in the kernels exists at harvest. This finding is of concern as these mycotoxins have been associated with several diseases in humans and animals [11,15-18]. In addition, consumers' exposure and the subsequent exertion of toxic effects is plausible because of the lack of regulation in foods. Moreover, a recent study carried out by Huybrechts et al. [19] has related chronic exposure of low-dose Alternaria mycotoxins in food commodities to the onset of colorectal cancer in humans. In the same study, the multi-mycotoxin occurrence was also related to the high risk of colorectal cancer onset. The authors pointed out that based on external exposure assessments, the highest contribution in increasing the cancer onset was related to the consumption of bread and other wheat-derived products.

The high level of Alternaria contamination of wheat collected in Tuscany, and the fact that further concern can be derived by the common incidence of other mycotoxins-especially those produced by Fusarium - opens questions on their possible impact on antagonistic, additive, or synergistic toxicological interactions. Furthermore, an increased attention on Alternaria mycotoxins and their producing species occurrence in wheat, and the need to more carefully evaluate a legislation aimed to regulate their occurrence in food, is required; although, wider and more consistent studies at Italian and worldwide levels are imperative to address decision makers at institutional level. 


\section{Conclusions}

The level of Alternaria contamination in wheat samples was mostly high along the four years investigated. This study relates for the first time the production of main Alternaria mycotoxins, $\mathrm{AOH}$, AME, ALT, and TA, to strains belonging to different species and sections of the Alternaria genus, genetically characterized according to the new revised taxonomy proposed by Lawrence et al. $[25,37,38]$ and Woodenberg et al. [36].

The higher occurrence on the wheat kernels of strains belonging to Section Alternaria compared with Section Infectoriae is thus a reason for further concern because of the dramatic differences in the mycotoxin profiles highlighted above.

\section{Material and Methods}

\subsection{Origin of Wheat Samples}

The one hundred wheat fields analyzed (48 fields of soft wheat and 52 fields of durum wheat) were located in different areas of the Tuscany region, in four consecutive crop seasons: 2013, 2014, 2015, and 2016. Forty-one fields in the first year, 31 fields in the second year, 15 fields in the third years, and 13 fields in the last year were considered (Table 1). Samples of wheat kernels were randomly collected from each field.

Meteorological data were collected, to investigate the eventual influence of climatic conditions on the occurrence of Alternaria species in wheat kernels. In particular, rainfall distribution and temperature were measured in each geographical areas in which the fields were located using weather stations. The data were used to obtain mean values of rainfall and temperatures for each crop season. As Alternaria species mostly colonize wheat kernels in the last growth stages, mean values of climatic parameters from heading stage to harvest are also reported in Table 2.

\subsection{Isolation and Morphological Characterization of Alternaria Strains}

For each sample, 100 representative kernels were superficially disinfected in a $2 \%$ sodium hypochlorite solution for $2 \mathrm{~min}$, washed twice with sterile distilled water for $1 \mathrm{~min}$, and then plated (10 kernels/plate) on potato dextrose agar (PDA) added with pentachloronitrobenzene (PCNB; $\left.500 \mathrm{mg} \mathrm{L}^{-1}\right)$, streptomycin $\left(100 \mathrm{mg} \mathrm{L}^{-1}\right)$, and neomycin $\left(50 \mathrm{mg} \mathrm{L}^{-1}\right)$. After five days of incubation at $25 \pm 1{ }^{\circ} \mathrm{C}$ under fluorescent light (12 h of photoperiod), for each sample, total fungal contamination and Alternaria contamination were detected. Based on morphological traits, representative Alternaria strains were selected to obtain mono-conidial cultures. Spores of Alternaria, collected by colonies originated from infected kernels, were spread at low density on water agar (WA: $20 \mathrm{~g} \mathrm{~L}^{-1}$ agar Oxoid n. 3) and singly collected after germination, using a dissection microscope, on potato carrot agar (PCA: infusion from $20 \mathrm{~g}$ peeled and sliced white potatoes, $20 \mathrm{~g}$ carrot kept at $60^{\circ} \mathrm{C}$ for $1 \mathrm{~h} ; 15 \mathrm{~g} \mathrm{~L}^{-1}$ agar Oxoid n. 3). According to Simmons [20], after seven days of incubation at $25 \pm 1{ }^{\circ} \mathrm{C}$, under an alternating light/darkness cycle of $12 \mathrm{~h}$ photoperiod, Alternaria isolates were morphologically identified and grouped on the basis of sporulation model and colony morphology.

\subsection{DNA Extraction}

One hundred and thirty-four Alternaria mono-conidial strains were cultured for three days on cellophane disks overlaid on PDA plates at $25^{\circ} \mathrm{C}$. Afterwards, mycelium of each strain was collected by scraping, frozen, and lyophilized.

Genomic DNA was extracted and purified from powdered lyophilized mycelia (10-15 mg) using the "Wizard Magnetic DNA Purification System for Food" kit (Promega Corporation, Madison, WI, USA), according to the manufacturer's protocol. Quantity and integrity of DNA were checked at Thermo-Scientific Nanodrop (LabX, Midland, ON, Canada) and by comparison with a standard DNA (1 kb DNA Ladder, Fermentas GmbH, St. Leon-Rot, Germany) on 0.8\% agarose gel after electrophoretic separation. 


\subsection{PCR Amplifications and DNA Sequencing}

Allergen alt a 1 (alt), glyceraldehyde-3-phosphate dehydrogenase ( $g p d)$, and translation elongation factor $1 \alpha$ (tef-1a) genes were selected for a molecular characterization using a multi-locus sequence approach. For PCR reactions, the following specific primer pairs were used: alt-for/alt-rev [21], gdp1/gdp2 [43], and Alt-tef1/Alt-tef2 [8].

Polymerase chain reaction mixture $(15 \mu \mathrm{L})$ contained $15 \mathrm{ng}$ of DNA template, $0.45 \mu \mathrm{L}$ of each primer $(10 \mathrm{mM}), 0.3 \mu \mathrm{L}$ of dNTPs $(10 \mathrm{mM})$, and $0.075 \mu \mathrm{L}$ of Hot Master Taq DNA Polymerase $(1 \mathrm{U} / \mu \mathrm{L}$; 5 Prime). The three fragments were amplified according to PCR conditions reported in Somma et al. [8]. The amplification of tef and alt1a genes was carried out with the following parameters: one initial denaturation stage at $95^{\circ} \mathrm{C}$ for $2 \mathrm{~min}$, followed by 35 or 40 cycles, each consisting of $30 \mathrm{~s}$ of denaturation at $95{ }^{\circ} \mathrm{C} ; 30 \mathrm{~s}$ of annealing at $58^{\circ} \mathrm{C}$ or $55^{\circ} \mathrm{C}$ for alt $1 a$ and tef genes, respectively; $50 \mathrm{~s}$ of extension at $72{ }^{\circ} \mathrm{C}$; and a final extension stage of $7 \mathrm{~min}$ at $72{ }^{\circ} \mathrm{C}$. The thermal cycler parameters for $g p d$ gene were as follows: one initial denaturation stage at $95^{\circ} \mathrm{C}$ for $2 \mathrm{~min}$, followed by 35 cycles, each consisting of $50 \mathrm{~s}$ of denaturation at $95^{\circ} \mathrm{C}, 50 \mathrm{~s}$ of annealing at $59^{\circ} \mathrm{C}, 60 \mathrm{~s}$ of extension at $72{ }^{\circ} \mathrm{C}$, and a final extension stage of $7 \mathrm{~min}$ at $72{ }^{\circ} \mathrm{C}$.

The PCR products were visualized with UV after electrophoretic separation in 1X TAE buffer, on $1.5 \%$ agarose gel.

PCR products were purified with the enzymatic mixture Exo/FastAP (Exonuclease I, FastAPthermosensitive alkaline phosphatase, Thermo Fisher Scientific (Waltham, MA, USA) and sequenced for both strand with Big Dye Terminator Cycle Sequencing Ready Reaction Kit (Applied Biosystems, Foster City, CA, USA), according to the manufacturer's recommendations. Both strands were purified by filtration through Sephadex G-50 (5\%) (Sigma-Aldrich, Saint Louis, MO, USA) and sequenced in "ABI PRISM 3730 Genetic Analyzer" (Applied Biosystems, Foster City, CA, USA).

\subsection{Phylogenetic Analyses}

For each gene fragment, the FASTA sequences were obtained by using BioNumerics software (Applied Maths, Kortrijk, Belgium). Gene sequences of Alternaria species reference strains, listed in Table 4, were downloaded by the National Center for Biotechnology Information (NCBI) and "Alternaria Genomes Database" (AGD). All sequences of the three genes (alt-a-1, gpd, and tef1-a) considered have been aligned using the Clustal W algorithm [44] and the phylogenetic relationships were studied using the maximum parsimony method with MEGA software version 7 [45]. The bootstrap analyses [46] were conducted to determine the confidence of internal nodes using a heuristic search with 1000 replicates, removing gaps. The section designations were made according to Lawrence et al. [37].

Table 4. GenBank accession number of Alternaria species sequences used in this study.

\begin{tabular}{|c|c|c|c|c|c|}
\hline Alternaria Species & Strain Number & \multicolumn{4}{|c|}{ GenBank Accession Numbers } \\
\hline A. alternarina & CBS 119396 & JQ905113 & JQ905170 & JQ905142 & NCBI \\
\hline A. alternata & ATCC66891 & AATCTG00058 & AATCTG00420 & AATCTG00079 & AGD \\
\hline A. alternata & BMP 0270 & AA2CTG00036 & AA2CTG00134 & AA2CTG00228 & AGD \\
\hline A. angustiovoidea & EGS 36-172 & JQ646398 & JQ646315 & JQ672465 & NCBI \\
\hline A. betae-kenyensis & CBS 118810 & JQ905104 & JQ905161 & KP125197 & NCBI \\
\hline A. brassicicola & EEB 2232 & AY563311 & AY278813 & JQ672450 & NCBI \\
\hline A. burnsii & CBS 107.38 & JQ646388 & JQ646305 & KP125198 & NCBI \\
\hline A. californica & EGS 52-082 & JQ646373 & JQ646285 & JQ672433 & NCBI \\
\hline A. capsici & BMP 0180 & AY563298 & AY562408 & ACSCTG01642 & NCBI/AGD \\
\hline
\end{tabular}


Table 4. Cont.

\begin{tabular}{|c|c|c|c|c|c|}
\hline Alternaria Species & Strain Number & \multicolumn{4}{|c|}{ GenBank Accession Numbers } \\
\hline A. citrimacularis & BC2-RLR-17s & JQ646407 & JQ646323 & JQ672466 & NCBI \\
\hline A. crassa & BMP 0172 & AY563293 & AY278804 & JQ672489 & NCBI \\
\hline A. dauci & BMP 0167 & AY563292 & AY278803 & ADCCTG02999 & NCBI/AGD \\
\hline A. ethzedia & EGS 37-143 & AY563284 & AY278795 & JQ672427 & NCBI \\
\hline A. gaisen & BMP 2338 & ACRCTG04151 & ACRCTG04221 & ACRCTG02961 & AGD \\
\hline A. gaisen & BMP 0243 & JQ646400 & JQ646317 & JQ672463 & NCBI \\
\hline A. grisea & CBS 107.36 & JQ646393 & JQ646310 & JQ672471 & NCBI \\
\hline A. hordeicola & EGS 50-184 & JQ646372 & JQ646284 & JQ672425 & NCBI \\
\hline A. incomplexa & EGS 17-103 & JQ646374 & JQ646287 & JQ672422 & NCBI \\
\hline A. mali & BMP 3064 & AGSCTG02862 & AGSCTG00707 & AGSCTG00243 & AGD \\
\hline A. macrospora & BMP 1949 & AMRCTG01538 & AMRCTG02006 & AMRCTG00463 & AGD \\
\hline A. metachromatica & EGS 38-132 & AY563285 & AY762956 & JQ672437 & NCBI \\
\hline A. novae-zelandiae & EGS 48-092 & JQ646379 & JQ646296 & JQ672418 & NCBI \\
\hline A. oregonensis & EGS 29-194 & AY563283 & AY762957 & JQ672428 & NCBI \\
\hline A. perangusta & BMP 2336 & JQ646403 & JQ646319 & JQ672477 & NCBI \\
\hline A. photistica & EGS 35-172 & AY563282 & AY562402 & JQ672417 & NCBI \\
\hline A. rhadina & CBS 595.93 & JQ646399 & JQ646316 & JQ672470 & NCBI \\
\hline A. rosae & EGS 41-130 & JQ646370 & JQ646279 & JQ672414 & NCBI \\
\hline A.solani & CBS 116651 & AY563299 & KC584139 & КС584688 & NCBI \\
\hline A. tangelonis & BMP 2327 & ADCCTG06617 & ADCCTG03746 & ADCCTG02999 & AGD \\
\hline
\end{tabular}

* NCBI = National Center for Biotechnology Information; AGD = Alternaria Genome Database.

\subsection{Mycotoxins Extraction}

The method used for mycotoxin analysis is based on that described by Rubert et al. [47] with some modifications. The samples were finely ground with an Oster Classic grinder $(220-240 \mathrm{~V}, 50 / 60 \mathrm{~Hz}$, 600W; Madrid, Spain). Five grams of each homogenized sample were weighed in a $50 \mathrm{~mL}$ plastic tube and $25 \mathrm{~mL}$ of methanol was added. The extraction was carried out using an Ultra Ika T18 basic Ultra-turrax, Ika, (Staufen, Germany), for $3 \mathrm{~min}$. The extract was centrifuged at $4000 \times$ rpm for $5 \mathrm{~min}$ at $5{ }^{\circ} \mathrm{C}$. One milliliter of the supernatant was filtered through a $13 \mathrm{~mm} / 0.22 \mu \mathrm{m}$ nylon filter and diluted before injection into high performance liquid chromatography associated with a diode array detector (LC-DAD). All the extractions were carried out in triplicate.

HPLC Analysis

Alternariol, AME, ALT, and TA were determined using Merk HPLC with a diode array detector (LC-DAD) L-7455 (Merk, Darmstadt, Germany) at $256 \mathrm{~nm}$ and Hitachi Software Model D-7000 version 4.0 was used for data analysis. A Gemini $\mathrm{C}_{18}$ column (Phenomenex, Torrance, CA, USA) $4.6 \times 150 \mathrm{~mm}$, $3 \mu \mathrm{m}$ particle size was used as the stationary phase. Themobile phase consisted of two eluents, namely eluent $\mathrm{A}$ (water with $50 \mu \mathrm{L} / \mathrm{L}$ trifluoroacetic acid) and eluent $\mathrm{B}$ (acetonitrile with $50 \mu \mathrm{L} / \mathrm{L}$ trifluoroacetic acid). A gradient program with a constant flow rate of $1 \mathrm{~mL} / \mathrm{min}$ was used, starting with $90 \% \mathrm{~A}$ and $10 \% \mathrm{~B}$, reaching 50\% B after $15 \mathrm{~min}$ and $100 \% \mathrm{~B}$ after $20 \mathrm{~min}$. Then, 100\% B was maintained for $1 \mathrm{~min}$. Thereafter, the gradient was returned to $10 \% \mathrm{~B}$ in $1 \mathrm{~min}$ and allowed to equilibrate for $3 \mathrm{~min}$ 
before the next analysis [48]. The limit of detection (LOD) and quantification (LOQ) of the method used were of 0.01 and $0.1 \mathrm{ppm}$, respectively.

The data on the mycotoxin production were statistically processed using the Prism 5 software (La Jolla, CA, USA, www.graphpad.com).

Supplementary Materials: The following are available online at http://www.mdpi.com/2072-6651/10/11/ 472/s1, Table S1: Mean value and range of fungal contamination detected in the 100 wheat samples collected throughout the Tuscany region, over four consecutive crop seasons (2013-2016). Table S2: Phylogenetic clades reported in Figure 1 of the 134 strains identified using multilocus sequence approach, isolated from 100 wheat samples collected throughout the Tuscany region over four consecutive crop seasons (2013-2016).

Author Contributions: Conceptualization, A.M.; Methodology, A.M., A.S.; Validation, A.M., A.S., A.V., F.A.R., M.M., S.S., C.L., G.M.; Formal analysis, F.A.R., M.M., S.S., C.L., A.V.; Investigation, F.A.R., M.M., A.V., S.S., C.L.; Resources, A.M., A.S., A.F.L.; A.V., F.A.R., M.M., S.S., C.L., G.M.; Data Curation, A.S., A.V., F.A.R., M.M., C.L., G.M.; Writing-Original Draft Preparation, A.M., F.A.R., M.M.; Writing-Review \& Editing, A.M., A.S., A.F.L.; A.V., F.A.R., M.M., S.S., C.L., G.M.; Visualization, A.M., F.A.R., M.M., C.L., G.M.; Supervision, A.M.; Project Administration, A.M.; Funding Acquisition, A.F.L.

Funding: This research received no external funding.

Conflicts of Interest: The authors declare no conflict of interest.

\section{References}

1. ISTAT. Available online: www.agri.istat.it (accessed on 11 November 2018).

2. Alexander, J.; Benford, D.; Boobis, A.; Ceccatelli, S.; Cottrill, B.; Cravedi, J.; Di Domenico, A.; Doerge, D.; Dogliotti, E.; Edler, L.; et al. Scientific opinion on the risks for animal and public health related to the presence of Alternaria toxins in feed and food. EFSA J. 2011, 9, 2407.

3. Prabhu, A.S.; Prasada, R. Pathological and epidemiological studies on leaf blight of wheat caused by Alternaria triticina. Indian Phytopathol. 1966, 19, 95-112.

4. Kulshrestha, V.P.; Rao, M.V. Genetics of resistance to an isolate of Alternaria triticina causing leaf blight of wheat. Euphytica 1976, 25, 769-775. [CrossRef]

5. Chaurasia, S.; Chand, R.; Joshi, A. Relative dominance of Alternaria triticina Pras. et Prab. and Bipolarissorokiniana (Sacc.) Shoemaker in different growth stages of wheat (T. aestivum L.). J. Plant Dis. Prot. 2000, 107, 176-181.

6. Logrieco, A.; Moretti, A.; Solfrizzo, M. Alternaria toxins and plant diseases: And overview of origin, occurrence and risks. World Mycotoxin J. 2009, 2, 129-140. [CrossRef]

7. Amatulli, M.T.; Fanelli, F.; Moretti, A.; Mulè, G.; Logrieco, A.F. Alternaria species and mycotoxins associated to black point of cereals. Mycotoxins 2013, 63, 39-46. [CrossRef]

8. Somma, S.; Amatulli, M.T.; Masiello, M.; Moretti, A.; Logrieco, A.F. Alternaria species associated to wheat black point identified through a multilocus sequence approach. Int. J. Food Microbiol. 2018, under review.

9. Kashem, M.A.; Sultana, N.; Samanta, S.C.; Kamal, A.M.A. Biochemical changes in wheat seed due to the effect of black-point at different levels of maturing. Pak. J. Sci. Ind. Res. 1999, 42, 89-92.

10. Wang, W.; Jones, C.; Ciacci-Zanella, J.; Holt, T.; Gilchrist, D.G.; Dickman, M.B. Fumonisins and Alternaria alternata lycopersici toxins: Sphinganine analog mycotoxins induce apoptosis in monkey kidney cells. Proc. Natl. Acad. Sci. USA 1996, 93, 3461-3465. [CrossRef] [PubMed]

11. Ostry, V. Alternaria mycotoxins: An overview of chemical characterization, producers, toxicity, analysis and occurrence in foodstuffs. World Mycotoxin J. 2008, 1, 175-188. [CrossRef]

12. Patriarca, A.; Azcarate, M.P.; Terminiello, L.; Fernández Pinto, V. Mycotoxin production by Alternaria strains isolated from Argentinean wheat. Int. J. Food Microbiol. 2007, 119, 219-222. [CrossRef] [PubMed]

13. Lee, H.B.; Patriarca, A.; Magan, N. Alternaria in Food: Ecophysiology, Mycotoxin Production and Toxicology. Mycobiology 2015, 43, 93-106. [CrossRef] [PubMed]

14. Da Cruz Cabrala, L.; Terminiello, L.; Pinto, V.F.; Fog, K.; Patriarca, N.A. Natural occurrence of mycotoxins and toxigenic capacity of Alternaria strains from mouldy peppers. Int. J. Food Microbiol. 2016, 7, 155-160. [CrossRef] [PubMed]

15. Liu, G.T.; Qian, Y.Z.; Zhang, P.; Dong, Z.M.; Shi, Z.Y.; Zhen, Y.Z.; Miao, J.; Xu, Y.M. Relationships between Alternaria alternata and oesophageal cancer. IARC Sci. Publ. 1991, 105, 258-262. 
16. Steyn, P.S.; Rabie, C.J. Characterization of magnesium and calcium tenuazonate from Phomasorghina. Phytochemistry 1976, 15, 1977-1979. [CrossRef]

17. Yekeler, H.; Bitmis, K.; Ozcelik, N.; Doymaz, M.Z.; Calta, M. Analysis of toxic effects of Alternaria toxins on oesophagus of mice by light and electron microscopy. Toxicol. Pathol. 2001, 29, 492-497. [CrossRef] [PubMed]

18. Schrader, T.J.; Cherry, W.; Soper, K.; Langlois, I. Further examination of the effects of nitrosylation on Alternaria alternata mycotoxin mutagenicity in vitro. Mutat. Res. 2006, 606, 61-71. [CrossRef] [PubMed]

19. Huybrechts, I.; De Ruyck, K.; De Saeger, S.; De Boevre, M. Uniting large-scale databeses to unravel the impact of chronic multi-mycotoxins exposures on colorectal cancer incidence in Europe. In Proceedings of the 2nd MycoKey International Conference, Wuhan, China, 16-18 September 2018; China Agricultural Science and Technology Press: Beijing, China, 2018; pp. 181-183.

20. Simmons, E.G. Alternaria: An Identification Manual, 6th ed.; CBS Fungal Biodiversity Centre: Utrecht, The Netherlands, 2007.

21. Hong, S.G.; Cramer, R.A.; Lawrence, C.B.; Pryor, B.M. Alt a1 allergen homologs from Alternaria and related taxa: Analysis of phylogenetic content and secondary structure. Fungal Genet. Biol. 2005, 42, 119-129. [CrossRef] [PubMed]

22. Hong, S.G.; Maccaroni, M.; Figuli, P.J.; Pryor, B.M.; Belisario, A. Polyphasic classification of Alternaria isolated from hazelnut and walnut fruit in Europe. Mycol. Res. 2006, 110, 1290-1300. [CrossRef] [PubMed]

23. Andersen, B.; Sorensen, J.L.; Nielsen, K.F.; van den Ende, B.G.; de Hoog, S. A polyphasic approach to the taxonomy of the Alternaria infectoria species-group. Fungal Genet. Biol. 2009, 46, 642-656. [CrossRef] [PubMed]

24. Somma, S.; Pose, G.; Pardo, A.; Mulè, G.; Pinto, V.F.; Moretti, A.; Logrieco, A.F. AFLP variability, toxin production, and pathogenicity of Alternaria species from Argentinean tomato fruits and puree. Int. J. Food Microbiol. 2011, 145, 414-419. [CrossRef] [PubMed]

25. Lawrence, D.P.; Gannibal, P.B.; Peever, T.L.; Pryor, B.M. The sections of Alternaria: Formalizing species-group concepts. Mycologia 2013, 105, 530-546. [CrossRef] [PubMed]

26. Woudenberg, J.H.C.; Groenewald, J.Z.; Binder, M.; Crous, P.W. Alternaria redefined. Stud. Mycol. 2013, 75, 171-212. [CrossRef] [PubMed]

27. Polizzotto, R.; Andersen, B.; Martini, M.; Grisan, S.; Assante, G.; Musetti, R. A polyphasic approach for the characterization of endophytic Alternaria strains isolated from grapevines. J. Microbiol. Methods 2012, 88, 162-171. [CrossRef] [PubMed]

28. Bottalico, A.; Perrone, G. Toxigenic Fusarium species and mycotoxins associated with head blight in small-grain cereals in Europe. Eur. J. Plant Pathol. 2002, 108, 611-624. [CrossRef]

29. Moretti, A.; Logrieco, A. Climate change effects on the biodiversity of mycotoxigenic fungi and their mycotoxins in preharvest conditions in Europe. In Climate Change and Mycotoxins; Botana, L.M., Sainz, J.M., Eds.; Walter de Gruyter GmbH \& Co KG: Berlin, Germany, 2015; pp. 91-108, ISBN 978-3-11-033305-3.

30. Arcella, D.; Eskola, M.; Gómez Ruiz, J.A. Scientific report on the dietary exposure assessment to Alternaria toxins in the European population. EFSA J. 2016, 14. [CrossRef]

31. Solhaug, A.; Eriksen, G.S.; Holme, J.A. Mechanisms of action and toxicity of the mycotoxin alternariol: A review. Basic Clin. Pharmacol. Toxicol. 2016, 119, 533-539. [CrossRef] [PubMed]

32. Benassi, F.; Zid, M.; Rhouma, A.; Bacha, H.; Hajlaoui, M.R. First report of Alternaria species associated with black point of wheat in Tunisia. Ann. Microbiol. 2009, 59, 465-467. [CrossRef]

33. Kahl, S.M.; Ulrich, A.; Kirichenko, A.A.; Muller, M.E.H. Phenotypic and phylogenetic segregation of Alternaria infectoria from small-spored Alternaria species isolated from wheat in Germany and Russia. J. Appl. Microbiol. 2015, 119, 1637-1650. [CrossRef] [PubMed]

34. Perello, A.; Moreno, M.; Sisterna, M. Alternaria infectoria species-group associated with Black point of wheat in Argentina. Plant Pathol. 2008, 57, 379. [CrossRef]

35. Kammoun, G.L.; Bensassi, F.; Hattab, M.M.; Rhouma, A.; Bacha, H.; Hajlaoui, M.R. Identification of Alternaria species recovered from stored durum wheat kernels in Tunisia. Tunis. J. Plant Prot. 2014, 9, 119-129.

36. Woudenberg, J.H.C.; Seidl, M.F.; Groenewald, J.Z.; De Vries, M.; Stielow, J.B.; Thomma, B.P.H.J.; Crous, P.W. Alternaria section Alternaria: Species, formaespeciales or pathotypes? Stud. Mycol. 2015, 82, 1-21. [CrossRef] [PubMed]

37. Lawrence, D.P.; Rotondo, F.; Gannibal, P.B. Biodiversity and taxonomy of the pleomorphic genus Alternaria. Mycol. Prog. 2016, 15, 3. [CrossRef] 
38. Lawrence, D.P.; Gannibal, P.B.; Peever, T.L.; Dugan, F.M.; Pryor, B. Characterization of Alternaria isolates from the infectoria species-group and a new taxon from Arrhenatherum, Pseudoalternaria arrhenatheria sp. nov. Mycol. Prog. 2014, 13, 257-276. [CrossRef]

39. Simmons, E. Alternaria themes and variations (106-111). Mycotaxon 1994, 50, 409-427.

40. Simmons, E.G. Alternaria themes and variations (22-26). Mycotaxon 1986, 25, 287-308.

41. Simmons, E. Alternaria themes and variations (305-309) Lewia/Alternaria revisited. Mycotaxon 2002, 83, 127-145.

42. Poursafar, A.; Ghosta, Y.; Orina, A.S.; Gannibal, P.B.; Nikkhah, M.J.; Lawrence, D.P. Taxonomic study on Alternaria sections Infectoriae and Pseudoalternaria associated with black (sooty) head mold of wheat and barley in Iran. Mycol. Prog. 2018, 17, 343-356. [CrossRef]

43. Berbee, M.L.; Pirseyedi, M.; Hubbard, S. Cochliobolus phylogenetics and the origin of known, highly virulent pathogens, inferred from ITS and glyceraldehyde-3-phosphate dehydrogenase gene sequences. Mycologia 1999, 91, 964-977. [CrossRef]

44. Thompson, J.D.; Higgins, D.G.; Gibson, T.J. CLUSTAL W: Improving the sensitivity of progressive multiple sequence alignment through sequence weighting, position-specific gap penalties and weight matrix choice. Nucleic Acids Res. 1994, 22, 4673-4680. [CrossRef] [PubMed]

45. Kumar, S.; Stecher, G.; Tamura, K. MEGA7: Molecular Evolutionary Genetics Analysis Version 7.0 for Bigger Datasets. Mol. Biol. Evol. 2016, 33, 1870-1874. [CrossRef] [PubMed]

46. Felsenstein, J. Confidence limits on phylogenies: An approach using the bootstrap. Evolution 1985, 39, 783-791. [CrossRef] [PubMed]

47. Rubert, J.; Dzuman, Z.; Vaclavikova, M.; Zachariasova, M.; Soler, C.; Hajslova, J. Analysis of mycotoxins in barley using ultra high liquid chromatography high resolution mass spectrometry: Comparison of efficiency and efficacy of different extraction procedures. Talanta 2012, 99, 712-719. [CrossRef] [PubMed]

48. Myresiotis, C.K.; Testempasis, S.; Vryzas, Z.; Karaoglanidis, G.S.; Mourkidou, P.E. Determination of mycotoxins in pomegranate fruits and juices using a QuEChERS-based method. Food Chem. 2015, 182, 81-88. [CrossRef] [PubMed] 